both harmful and beneficial, and the effects upon these of the widespread planning and industrial development of recent years is becoming a matter of significant importance in biological studies; and the co-operation of the corresponding societies in the study of systematics in relation to general biology, which will be discussed in a communication from Mr. H. W. Parker, should prove of assistance and value in effectively ascertaining the desired information by co-ordinated field observations upon specific subjects.
An innovation will this year be introduced at Cambridge when the delegates of the corresponding societies and their guests will dine together, Lord Onslow presiding. They will also attend an aftermoon garden party at the Cambridge Botanic Gardens as the guests of Prof. F. T. Brooks. The view has been expressed that the business of the Conference affords insufficient opportunity for that social contact which is considered desirable and can best be attained by such functions.

\title{
National Efforts in Cancer Treatment
}

$\mathrm{T}$ HE eighth annual reports of the National Radium Trust and Radium Commission, 1936-1937 (published in December 1937)* is of special interest in that it breaks away from the immediate task which confronted it in 1929 and now seeks to guide activities on a broader basis. The following paragraph, taken from p. 23, illustrates this :

"The Commission believes that to secure a reason. able standard of service for the treatment of cancer cases throughout the country there is need for the whole problem to be attacked by the Government along national lines. This belief is supported by the fact that only a proportion of patients suffering from cancer in sites suitable for treatment by radio. therapy are receiving that treatment".

With the resources initially placed at the disposal of the Trust and the Commission, it was decided that a practical beginning to the problem of using radium in the treatment of disease could best be obtained in the way the Commission strove, namely, to secure so far as possible the concentration of radium treat. ment at the large voluntary hospitals which provide teaching facilities. It was inevitable that this left large parts of the country unprovided with radium facilities, and in consequence centres other than the national centres were set up, so that a glance at the map provided on p. 2 of this report shows 13 national centres, 9 regional centres and one recognized hospital where the Commission has its immediate interests.

In the report for the preceding year, the National Radium Trust, in looking to future needs, stated that "The views of the Radium Commission as to the need for further considerable supplies of radium have received and are receiving anxious consideration, the more so as it seems clear that with the trend towards the use of larger units the ultimate need over the next few years will be far beyond the financial resources of the Trust". The Commission now sees this whole problem of the radiological treatment of cancer looming larger with each succeeding year.

This may occasion little surprise to those who have witnessed at close range the developments of radiological treatment, especially in cancer; but it may well be different for those who, with the constant reminder of cancer statistics in front of them, may question how valid is the warrant for any big extension of these services. The fact is that surgical and radiological methods of treatment are the only two methods which are practised on any scale in Great Britain, and with a death-rate not far short of 60,000 people yearly, it is really an urgent matter to make the most of what we have got.

* Eighth Annual Reports of the National Radium Trust and Radium Commission 1936-1937, including a Statistical Report. (Cmd. 5612.) Pp. 80. (London: H.M. Stationery Office.) 18. 3d. net.
Thirty years ago it was not unusual for people to exclaim as to how gladly money would be given for a cure for cancer. It has not been claimed in any one of the reports which have been issued from the Radium Commission that radium treatment is a cure for cancer, but it is claimed, and supported by the most carefully gleaned (not selected) statistics, that large numbers of cancer patients have been treated with radium and have successfully survived periods of five years. Since cancer is likely to recur in the body it is generally held to be unwise to use the term 'cure', but 'freedom from the disease' is a term which is accepted on a clinical basis, and the 'survival rate' is one which is of the first importance in adjudg. ing the value of any remedial measure.

To return to the belief expressed by the Com. mission that the treatment of cancer is a problem to be attacked by the Government. This is shared by many people, but the steps by which it could be carried out have never been laid down, and are but hinted at in the report in question. The Commission does, however, state that an increase of bed accom. modation at or in association with the existing national centres will be required. The words "at or in association with" suggest, and are probably intended to convey, that any such scheme could only be carried out with the active co-operation, possibly the direction, of the Ministry of Health. It is, in fact, very difficult to see, with the pressure upon the bed accommodation of voluntary hospitals all over Great Britain, how any large increase in treatment facilities could occur without very extensive building and staffing. The position is indeed one which calls for the most sympathetic consideration by the Ministry, because by far the greater proportion of radium therapy carried out at present is done at the voluntary hospitals, the part played by those under the direction of the Ministry being, in fact, relatively small, though doubtless locally very important. If, then, the best that we can offer in the way of treat. ment for cancer can only be shared by the whole country by the operation of some comprehensive scheme such as that outlined by the Commission, it is a plain duty to be undertaken.

It has been pointed out more than once that the first need of the population is to be fed, the second is to be housed, the third (perhaps) is to be educated. Then comes the question of fitness in health, and unfitness through ill-health. It may well be that the claims of the treatment of people suffering from cancer may be dislodged from the official mind by the claims of the really healthy, that money should first be spent on the attainment of physical fitness rather than on the relief of the sick.
S. Russ. 